\title{
PROPOSTA DE IMPLEMENTAÇÃO DO SISTEMA VAC (VELOCIDADE DE ATRAVESSAMENTO CONSTANTE) PARA MAXIMIZAR O PROCESSO PRODUTIVO: ESTUDO DE CASO NA TS INDÚSTRIA DE ETIQUETAS
}

\section{ARTIGO ORIGINAL}

LIMA, Ruth Thayanne Magalhães de ${ }^{1}$, SOUZA, Natalia da Silva², UCHOA, Samuel Bezerra $^{3}$, ALMEIDA, Victor da Silva $^{4}$, RAMOS, José Manoel da Silva ${ }^{5}$, ROBERTO, José Carlos Alves 6

LIMA, Ruth Thayanne Magalhães de. Et al. Proposta de implementação do sistema VAC (Velocidade de Atravessamento Constante) para maximizar o processo produtivo: estudo de caso na TS Indústria de Etiquetas. Revista Científica Multidisciplinar Núcleo do Conhecimento. Ano. 06, Ed. 11, Vol. 12, pp. 0524. Novembro 2021. ISSN: 2448-0959, Link de acesso: https://www.nucleodoconhecimento.com.br/administracao/implementacao-dosistema, DOI: 10.32749/nucleodoconhecimento.com.br/administracao/implementacao-do-sistema

\section{RESUMO}

Para que uma organização se mantenha no mercado, esta deve ter como princípio o objetivo de satisfazer as pessoas. Para isso, é indispensável verificar se o produto ou o serviço contém o nível de qualidade exigido por seus clientes. Neste sentido, este artigo apresenta-se como estudo de caso aplicado na TS Indústria de Etiquetas

\footnotetext{
${ }^{1}$ Graduando do curso de Administração.

${ }^{2}$ Graduando do curso de Administração.

${ }^{3}$ Graduando do curso de Administração.

${ }^{4}$ Coorientador. Mestre em Engenharia de Processos. Pós-Graduando em Neuropsicopedagogia Institucional. Especialista em Gestão Estratégica de RH. Graduado em Administração e Pedagogia.

${ }^{5}$ Coorientador. Especialista - MBA. Empresário. Consultor Empresarial de Gestão \& Negócios.

${ }^{6}$ Orientador. Mestre em Engenharia de produção, Especialista Logística empresarial e Graduado em Administração com Ênfase em Marketing.
}

RC: 101923

Disponível em:

https://www.nucleodoconhecimento.com.br/administracao/implementacao-do- 
e Comércio de Equipamentos de Informática Ltda., onde propõe-se a implementação do sistema VAC (Velocidade de Atravessamento Constante). Diante disto, o presente artigo, tem como questão norteadora: Como a implementação do sistema VAC (Velocidade de Atravessamento Constante) pode contribuir com a maximização do atendimento no prazo da demanda da carteira de pedidos na indústria de etiquetas? O objetivo geral deste estudo é introduzir um novo sistema na área de produção para contribuir com o aumento da produtividade, entrega no prazo e satisfação do cliente. A pesquisa estrutura-se com bases bibliográficas, métodos exploratórios e qualitativos. Como resultados, apresenta-se uma proposta que, por meio da ferramenta 5W2, aspira a implantação de ações em forma de plano de melhorias, o qual aponta novas metodologias que facilitam a gestão da empresa, de modo que estas táticas sejam elaboradas e empregadas conforme as necessidades encontradas.

Palavras-chave: Atendimento, Gestão, Informática, Sistema.

\section{INTRODUÇÃO}

O Brasil, por ser um país que possui uma vasta faixa de negócios, serviços e produtos, terá sempre elementos suficientes para serem divulgados e explorados pelo lado positivo e um próspero empreendedorismo, pois a confiabilidade na informação é um dos principais motivos para o crescimento e manutenção saudável das empresas que pretendem ter sucesso nesse ramo. No entanto, reconhece-se que a base de sobrevivência da organização é a qualidade, e que ela deve se fazer presente em todas as dimensões que influenciam na satisfação dos serviços ofertados.

O objetivo deste estudo consiste em introduzir um novo sistema na área de produção para contribuir com o aumento da produtividade, entrega no prazo e satisfação do cliente.

RC: 101923

Disponível em:

https://www.nucleodoconhecimento.com.br/administracao/implementacao-do-

sistema 
Zanella (2013) afirma que a pesquisa pretende desenvolver novos fundamentos científicos e com este intuito é necessário estruturar detalhadamente a perquirição; sendo assim, deve-se estipular: o que, por que, para quê, como e quando apurar os dados bibliográficos e científicos. Deste modo, busca-se reunir informações com o propósito de solucionar o problema de pesquisa de: como a implementação do sistema VAC (Velocidade de Atravessamento Constante) pode contribuir com a maximização do atendimento no prazo da demanda da carteira de pedidos na indústria de etiquetas?

Para tanto, a proposta de implementação do Sistema VAC ocorreu na empresa TS Indústria de Etiquetas do ramo industrial, com base em pesquisas bibliográficas, visitas técnicas e em questionários qualitativos e exploratórios; isto com o propósito de estimular, incentivar e clarificar todos os dados da empresa, visando atender às suas necessidades.

Reconhece-se que há um grande acervo de ferramentas que contribuem com a administração da organização e auxiliam em uma maior agregação de valor neste processo, promovendo vantagens competitivas para a organização. Todas as análises efetuadas para evidenciar aquela de maior qualificação para a organização descrevem-se por meio da metodologia de $5 \mathrm{~W} 2 \mathrm{H}$, que visa destacar os objetivos específicos, planejar, inserir etapas e esquematizar o método Kanban para o Sistema VAC.

Portanto, espera-se que com a inclusão das propostas seguintes a empresa possa atender a sua carteira de clientes e entregar os pedidos no devido prazo, trazendo lucros, maior satisfação dos clientes e o aumento de seu engajamento na cidade de Manaus.

\section{FUNDAMENTAÇÃO TEÓRICA}

O anseio por estudos anteriores ao abordado é a base de qualquer pesquisa que se destina a acrescentar e propagar erudições. Esta busca deve ocorrer por meio de

RC: 101923

Disponível em:

https://www.nucleodoconhecimento.com.br/administracao/implementacao-do- 
pesquisas bibliográficas, sendo estas concluídas ou não, variando conforme o foco do estudo.

Conforme Zanella (2013, p. 87), "a construção de um artigo científico segue a trajetória de uma pesquisa científica. É necessário, portanto, planejar o que será investigado, executar aquilo que foi projetado e comunicar os resultados".

\subsection{PLANEJAMENTO}

O planejamento é a função administrativa em que se determina antecipadamente quais são os objetivos que devem ser atingidos e como se deve fazer para alcançálos. Trata-se, pois, de um modelo teórico para a ação futura, que se inicia pela determinação dos objetivos, detalhando os planos necessários para atingi-los da melhor maneira possível. Planejar é definir os objetivos e escolher com antecedência o melhor caminho de ação para alcançá-los. O planejamento é uma escolha de onde se quer chegar, quando, como e em que sequência.

Conforme Jacobsen (2017), o planejamento pode ocorrer nos três níveis hierárquicos da organização e representa perspectivas que diferem-se entre si na dimensão do horizonte temporal, no grau de especificidade e na abrangência. Neste contexto, existe o planejamento estratégico, o planejamento tático e o planejamento operacional, que distinguem-se da observação, da experiência e da constatação de muitos analistas, executivos e consultores de que planos elaborados pelas empresas.

Costa (2017) afirma que a experiência e a história têm mostrado que a sobrevivência das organizações está ligada muito mais à sua flexibilidade e agilidade para enfrentar desafios e ameaças do que ao porte, estabilidade, poder ou domínio de mercado.

Segundo Marques (2015), é essencial que as organizações desenvolvam diferentes tipos de planejamentos, de forma que sejam aproveitados todos os recursos

RC: 101923

Disponível em:

https://www.nucleodoconhecimento.com.br/administracao/implementacao-dosistema 
disponíveis, proporcionando resultados grandes e contínuos. O autor destaca também que os planejamentos Estratégico, Tático e Operacional, são três instrumentos indispensáveis para efetivar as táticas empresariais.

\subsection{ADMINISTRAÇÃO DE TEMPOS E MÉTODOS}

O estudo de tempos e métodos é um instrumento básico, que possui os objetivos de eliminar o desperdício de esforço humano, adaptar os operários às tarefas, treinálos, especializá-los e estabelecer normas de execução do trabalho.

Negreiros e Lima (2011) relatam que o objetivo da engenharia de métodos é designar padrões, e que ao estudar de forma sistemática o tempo de um trabalho é possível definir o método mais habilitado e útil para realização da atividade. Com o registro e análise da atividade definidos, é possível encontrar métodos para que tal atividade seja realizada de uma maneira que aumente a produtividade.

$\mathrm{Na}$ atualidade, é necessário que a organização acomode seus colaboradores e os auxilie a efetuar as atividades de forma agradável e confortável, desenvolvendo assim uma melhor produtividade.

De acordo com Jaiswal; Sane e Karandikar (2016), é pela engenharia de métodos que em certa atividade se faz possível utilizar os recursos humanos e materiais da melhor forma.

No estudo de tempos e métodos, há um sistema que auxilia nas tomadas de decisões. As decisões dão forma a um sistema que permite a transformação das entradas e saídas de um produto ou serviço. Continuamente, o sistema recebe informações que permitem ao operador encontrar o melhor método possível, sendo ele capaz de aumentar a produção (FURLANI, 2020).

RC: 101923

Disponível em:

https://www.nucleodoconhecimento.com.br/administracao/implementacao-dosistema 


\subsection{SISTEMA DE ATRAVESSAMENTO CONSTANTE}

Criado por Caetano Caruso e Nélio Dias em 1989 e estabelecido por 2 anos em uma camisaria, o Sistema de Atravessamento Constante (VAC), foi introduzido pela primeira vez em 1993. A finalidade do VAC é reduzir o tempo de produção, equilibrar a capacidade, ser previsível, minimizar os passivos operacionais e conferir flexibilidade à produção (SISTEMA VAC, 2012).

Para que o sistema de atravessamento constante funcione de forma esperada, é indispensável que seu ciclo de operações esteja adequado, sendo assim, a sequência de operações e os tempos ajustados a cada ciclo devem ser planejados da melhor maneira.

Antunes (2018) afirma que, no tempo de atravessamento, a redução do tempo tem uma dependência com a minimização das esperas do lote e do processo produtivo, e por isso é imprescindível que se compreenda sobre as vastas esperas que ocorrem no processo produtivo.

\subsection{TIPOS DE LAYOUT PRODUTIVO}

O layout determina como os materiais, as pessoas e as informações fluem durante o processo produtivo. Com o aumento da concorrência no setor industrial, as empresas procuram melhorias que possam ter um maior benefício no tempo dos processos e das atribuições realizadas por seus colaboradores. Em diversas situações, o layout utilizado pelas empresas se torna um grande limitador, pois não é bem elaborado e, por isso, apresenta um rendimento ineficiente. Embora mudar o layout consuma tempo e custos, se bem estruturado pode trazer diversos benefícios à empresa.

Para Ballou (2011), o layout industrial é uma estrutura disposta por homens, máquinas e materiais, que juntamente integram o fluxo de ferramentas e o manejo

RC: 101923

Disponível em:

https://www.nucleodoconhecimento.com.br/administracao/implementacao-dosistema 
dos equipamentos que precisam de espaço adequado para movimentação, para que a armazenagem ocorra dentro do padrão de economia e rendimento.

Nunes (2013) explica que o estudo do arranjo físico tem por objetivo a melhor combinação de material, equipamento e mão de obra no espaço disponível relacionado aos sistemas de produção, contemplando assim um plano de instalação industrial que integra todos os métodos de produção em um grupo lógico e ordenado, cada qual desempenhando sua parcela de ajuda para o objetivo final, que é a melhora da produção.

O arranjo físico é visível a todos que entram em uma linha de produção. A disposição de máquinas e processos mostra de forma clara como o produto está sendo produzido e a forma como tudo se equilibra durante a operação, desde a entrada do insumo, seguindo para a transformação e acabamento, até o produto final, pronto para ser empacotado e enviado para a distribuição. $O$ arranjo físico nos mostra a história do processo e como tudo é produzido.

Os quatros principais tipos de layouts são: posicional ou fixo; funcional ou por processo; layout celular e layout por produtos ou em linha.

Um layout bem estruturado tem um fluxo eficiente entre as atividades, trazendo melhoras às áreas produtivas, obtendo assim facilidade nas tarefas administradas, reduzindo os problemas ergonômicos e administradas, reduzindo os problemas ergonômicos e tornando versátil os processos em que pode ocorrer possíveis mudanças ou adequações (SILVA, 2016).

\subsection{BALANCEAMENTO DE LINHAS DE PRODUÇÃO}

O balanceamento de linha interfere diretamente no layout dos equipamentos de produção, bem como na disposição do estoque de matérias primas e materiais acabados.

RC: 101923

Disponível em:

https://www.nucleodoconhecimento.com.br/administracao/implementacao-dosistema 
Segundo Assis (2011), balancear uma linha de produção significa distribuir todas as tarefas necessárias à produção de determinado produto pelos locais de trabalho definidos.

Balancear a linha de produção, para Tubino (2017), é definir todos os afazeres que serão executados, com 0 intuito de assegurar um tempo de processamento semelhante entre os postos de trabalho.

Portanto, o balanceamento de linha é utilizado para ajustar a produção às ânsias da demanda, em uma tentativa de unir o tempo de ação do produto em cada uma de suas operações sucessivas (ROCHA; OLIVEIRA, 2017).

\subsection{CONCEITO DE KANBAN}

Segundo Moura (2007), o Kanban é um método que reduz o tempo de espera, ou seja, diminui o estoque, melhorando toda a produtividade e coligando todas as linhas, operando de maneira uniforme e ininterrupta. A conversão da matéria prima em produtos acabados com tempo de espera igual ao tempo de curso da produção, elimina o tempo perdido em fila do material, bem como a ociosidade de material.

Sendo uma ferramenta de gestão de fluxo de trabalho e produção, o Kanban confere um melhor controle de processo e maior transparência do mesmo pelos membros que integram cada equipe. (SOUEID; ALVES, 2020).

Também é um método utilizado para melhorar a eficiência e eficácia de produção das empresas, aperfeiçoando os processos de produção, a logística na parte de movimentações e o término das demandas mais rapidamente, tudo isso com o menor custo.

RC: 101923

Disponível em:

https://www.nucleodoconhecimento.com.br/administracao/implementacao-dosistema 


\subsection{ETAPAS DE INTRODUÇÃO DO SISTEMA KANBAN}

O uso do sistema Kaban ocorre por meio de cartões que sinalizam o que está de fato acabando. São indicados com cores e até mesmo tamanho diferentes, que descrevem qual a tarefa tem que de ser realizada. O Kaban nada mais é do que um sistema que precisa ser ágil e visual para a execução do processo entre estoque e linha de produção. É necessário ser visual, pois por meio dos cartões é fácil identificar e visualizar a falta de material em determinado setor, ou seja, precisa ser visível para todos os colaboradores do setor.

Segundo Espinha (2019), O Kanban mostra muitas vantagens, seja na indústria ou dentro dos escritórios, que são: Priorizar as atividades, autonomia, diminuir os custos, ajuda mútua dos colaboradores e aumento da produtividade.

Para Implementar o Kanban em um software em desenvolvimento é necessário seguir etapas, sendo importante, primeiro, mapear o fluxo de trabalho para que se obtenha uma visão do processo, definindo, assim, um ponto de começo e um ponto final para controle. Após essa definição, o fluxo de trabalho é melhor visualizado. (ANDERSON, 2011).

\section{MATERIAIS E MÉTODOS}

O presente artigo tem como proposta a implementação do sistema VAC (velocidade de atravessamento constante) na indústria de etiquetas pesquisada, a fim de para determinar a capacidade de absorção das aquisições e alcançar precisão no planejamento.

\subsection{PROCEDIMENTOS METODOLÓGICOS}

A primeira parte do trabalho constituiu-se em um levantamento conceitual teórico preliminar, no qual a proposta foi baseada e elaborada a partir de materiais já

RC: 101923

Disponível em:

https://www.nucleodoconhecimento.com.br/administracao/implementacao-do$\underline{\text { sistema }}$ 
publicados, compostos principalmente por livros, artigos de periódicos e também de materiais disponíveis na Internet.

A segunda etapa, conclusiva, integrou a aplicação de técnicas para coleta de dados, com o propósito de reunir o máximo de informações, pois as análises de todos os dados são de grande importância para elaboração do diagnóstico da empresa, mapeamento do processo e identificação de seus pontos de melhorias.

Metodologia é o estudo do método, ou seja, o estudo sobre determinado fenômeno ou fato. São uma série de procedimentos técnicos e intelectuais para se obter conhecimento (ZANELLA, 2013).

\subsubsection{QUANTO À NATUREZA}

Os objetivos metodológicos foram desenvolvidos por meio de pesquisas exploratórias e descritivas, com o intuito de identificar as principais necessidades e falhas. Por meio dessas foi não somente possível elaborar um diagnóstico da empresa, mas também pôde-se propor possíveis soluções para o aperfeiçoamento profissional dos funcionários que trabalham na área da produção e planejamento.

É uma situação de pesquisa na qual o observador e o observado se encontram frente a frente e, também, onde o processo de coleta de dados se encontra no ambiente comum dos observados que passam a ser analisados como sujeitos que se relacionam no projeto de estudos. (MARCONI; LAKATOS, 2018).

\subsubsection{QUANTO AOS FINS}

Desta forma, o método que se enquadra é o dedutivo, pois, segundo o autor Prestes (2011), métodos dedutivos e a racionalização ou a combinação de ideias em sentido interpretativo têm mais valor que a experimentação caso a caso, ou seja, utiliza-se a dedução, raciocínio que caminha em geral para o particular.

RC: 101923

Disponível em:

https://www.nucleodoconhecimento.com.br/administracao/implementacao-dosistema 
Por fim, foi feita uma proposta de implantação de melhorias, que abrangeu a elaboração do modelo e a definição dos indicadores de desempenho no sistema VAC na empresa, pois a criação de um plano reduziu os custos e aumentou a produção, sanando os erros dentro da organização.

\subsubsection{QUANTO AOS MEIOS}

Podemos afirmar que, em virtude de várias formas de abordagem realizadas nessa pesquisa, o trabalho se encaixa na pesquisa descritiva, pois, segundo o autor Prestes (2011), na pesquisa descritiva se observam, registram, analisam, classificam e interpretam os fatos.

\subsection{CARACTERIZAÇÃO DA EMPRESA}

A pesquisa foi realizada em uma única etapa e se desenvolveu na empresa TS Indústria de Etiquetas e Comércio de Equipamentos de Informática Ltda., localizada no bairro Japiim, na cidade de Manaus - Am. A empresa é do segmento industrial de fabricação de etiquetas, produtos de escritório e equipamentos de informática, tendo seu público-alvo endereçado às empresas do distrito industrial.

Com área construída de $24 \mathrm{~m}^{2} \times 20 \mathrm{~m}^{2}$, é uma empresa que atua há mais de 10 anos nos segmentos de Etiquetas Adesivas em papéis diversificados, bobinas térmicas e impressoras.

Atualmente, a empresa conta somente com uma sede, situada no endereço informado acima, porém, já começou a focar seus esforços em ampliar seus serviços a outros bairros da cidade de Manaus.

RC: 101923

Disponível em:

https://www.nucleodoconhecimento.com.br/administracao/implementacao-dosistema 


\section{RESULTADOS E DISCUSSÕES}

$\mathrm{Na}$ etapa do Diagnóstico Organizacional, foi realizado um estudo, no qual foi possível conhecer sobre o desempenho de cada área da empresa, conforme mostrado no Gráfico 01: Média - desempenho por área funcional.

Gráfico 01 - Média - desempenho por área funcional

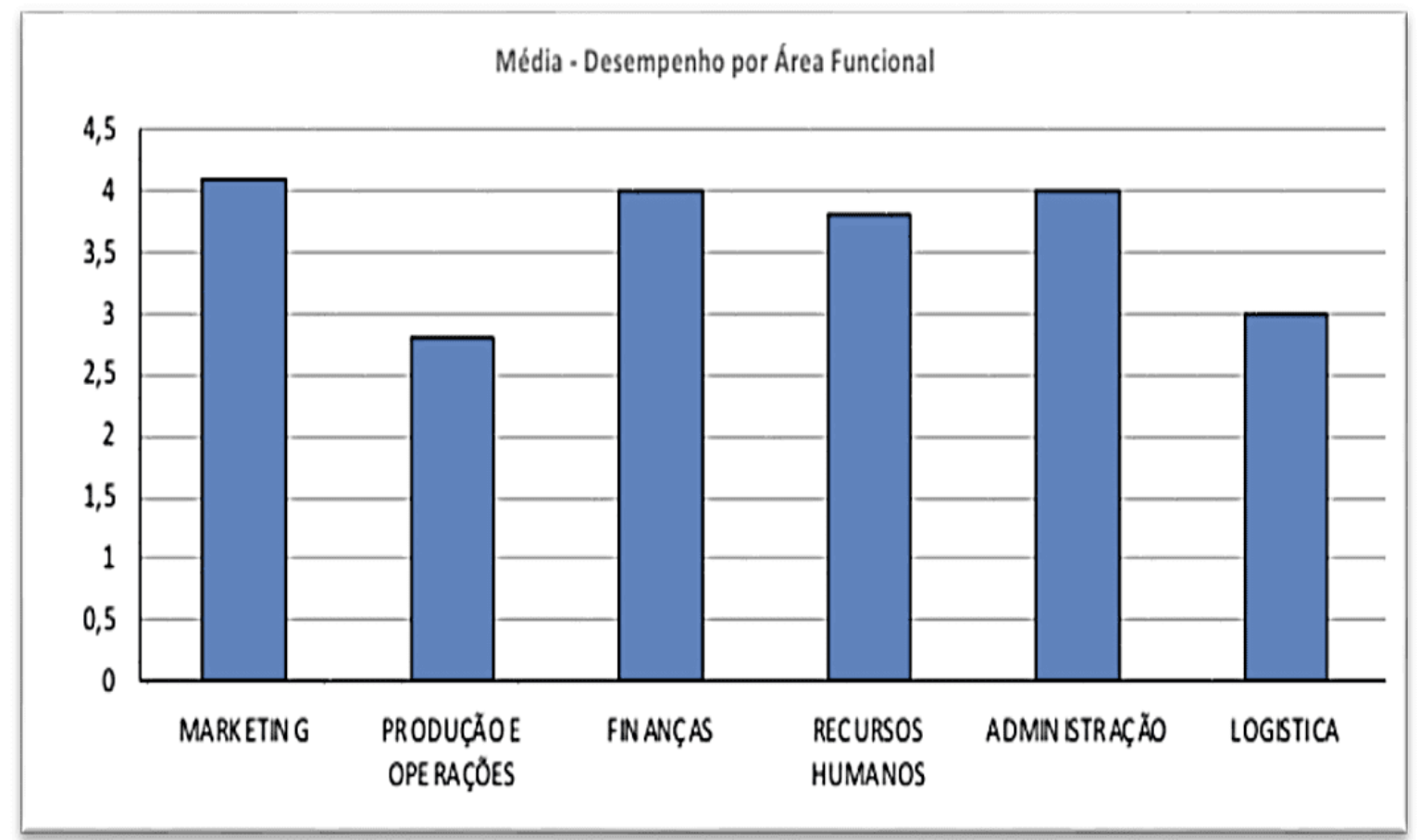

Fonte: Elaborado pelos autores do diagnóstico com base em coleta de dados, 2021.

Pôde-se observar que as áreas da organização com o melhor desempenho foram os setores de Marketing, Administração e Finanças. Já as áreas de Recursos Humanos e Logística obtiveram um desempenho mediano, restando a área de Produção e Operações como a área mais crítica da empresa.

RC: 101923

Disponível em:

https://www.nucleodoconhecimento.com.br/administracao/implementacao-dosistema 
Quadro 01 - Produção e Operações

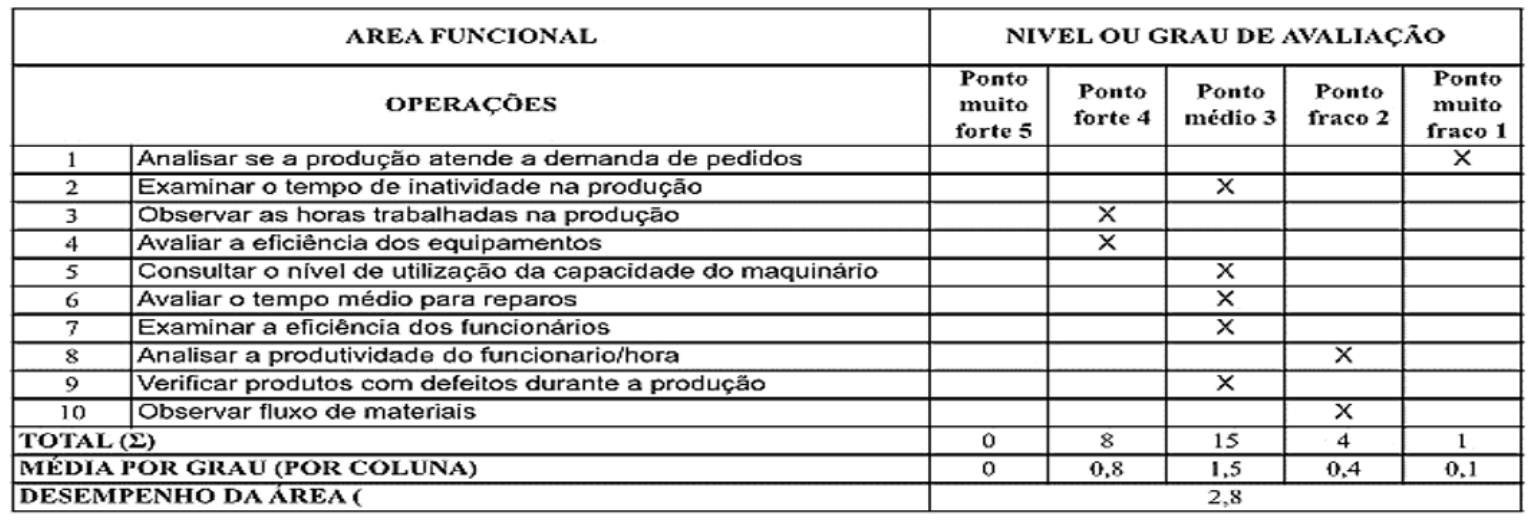

Fonte: Elaborado pelos autores do diagnóstico com base em coleta de dados, 2021.

Pode-se observar no quadro 01 que a área de produção e operações foi identificada como a mais crítica da organização, tendo dificuldade em atender a demanda de pedidos. A TS Indústria de Etiquetas é uma empresa que atende as grandes empresas do distrito industrial por meio da oferta de etiquetas em grandes quantidades, o que, ocasionalmente, pode acarretar em certa dificuldade na entrega dos pedidos dentro do prazo estipulado por conta do aumento repentino na demanda.

Portanto, a pergunta problema da pesquisa é: como a implementação do sistema VAC (Velocidade de Atravessamento Constante) pode contribuir com a maximização do atendimento no prazo da demanda da carteira de pedidos na indústria de etiquetas?

\subsection{PLANEJAMENTO DE AÇÕES:}

Planejamento de ações são etapas e passos que devem ser elaborados para se obter um caminho mais detalhado das atividades necessárias para atingir os objetivos desejados pela organização.

RC: 101923

Disponível em:

https://www.nucleodoconhecimento.com.br/administracao/implementacao-do- 
Quadro 02 - Ações Interventivas

\begin{tabular}{|c|c|c|c|c|}
\hline & Ações Interventivas & Cronologia & Duração & Custo \\
\hline 1 & $\begin{array}{l}\text { Aplicar um estudo teórico e treinamento } \\
\text { sobre o sistema VAC aos funcionários. }\end{array}$ & Setembro/2021 & 5 dias & $\begin{array}{l}R \$ \\
1.200,00\end{array}$ \\
\hline 2 & Alterar o Layout da área de produção & Setembro/2021 & 1 dia & $\begin{array}{l}R \$ \\
800,00\end{array}$ \\
\hline 3 & Balancear o fluxo de produção & Setembro/2021 & $1 \mathrm{dia}$ & $\mathrm{R} \$ 00,00$ \\
\hline 4 & $\begin{array}{l}\text { Introduzir o transporte entre cédulas } \\
\text { (Kanban) }\end{array}$ & Outubro/2021 & 4 dias & $\begin{array}{l}\mathrm{R} \$ \\
1.000,00\end{array}$ \\
\hline 5 & Aplicar o sistema VAC na empresa & Outubro/2021 & 15 dias & $\begin{array}{l}\mathrm{R} \$ \\
1.800,00\end{array}$ \\
\hline \multicolumn{4}{|c|}{ Total } & $\begin{array}{l}\mathrm{R} \$ \\
4.800,00\end{array}$ \\
\hline
\end{tabular}

Fonte: Elaborado pelos autores do diagnóstico, 2021.

\subsubsection{FERRAMENTA DA QUALIDADE PARA IMPLEMENTAÇÃO $5 \mathrm{~W} 2 \mathrm{H}$}

É por meio da ferramenta da qualidade $5 \mathrm{w} 2 \mathrm{~h}$ que desenvolvemos soluções para cada ação interventiva. $5 \mathrm{~W} 2 \mathrm{H}$ são um conjunto de perguntas formuladas para que se obtenha soluções eficientes para as ações e questões da organização, auxiliando também na elaboração do plano de ação e mapeamento de processos.

A ferramenta $5 \mathrm{Ws}$ e $2 \mathrm{Hs}$ são perguntas que têm como objetivo gerar respostas que esclareçam o problema a ser resolvido, com o intuito de encontrar as falhas no processo da organização. (SELEME E STADLER, 2012).

RC: 101923

Disponível em:

https://www.nucleodoconhecimento.com.br/administracao/implementacao-do- 


\subsubsection{APLICAR UM ESTUDO TEÓRICO E TREINAMENTO SOBRE O SISTEMA VAC AOS FUNCIONÁRIOS}

Obter conhecimento sobre o sistema que será aplicado na empresa é de extrema importância para que tudo ocorra como o esperado. Os funcionários devem estar informados sobre o problema e sua proposta de solução, para que assim possam se empenhar e colaborar para que o sistema aplicado funcione.

É juntamente com o treinamento, que é o estudo prático de uma atividade, que se traz aos colaboradores da organização mais habilidade e confiabilidade para desempenharem suas determinadas funções.

Quadro 03 - 5w2h - Aplicar um estudo teórico e treinamento sobre o sistema VAC aos funcionários

\begin{tabular}{|c|c|c|}
\hline What & O quê? & $\begin{array}{l}\text { Uma aula oral e um treinamento sobre como funcionará o } \\
\text { sistema VAC na empresa. }\end{array}$ \\
\hline Nhy & Por quê? & $\begin{array}{l}\text { Para que os funcionários obtenham conhecimento e saibam } \\
\text { como desempenhar sua função sobre o sistema a ser aplicado } \\
\text { na organização. }\end{array}$ \\
\hline Where & Onde? & TS Indústria de Etiquetas \\
\hline When & Quando? & Primeira semana de setembro de 2021 \\
\hline Who & Quem? & Departamento de Recursos Humanos \\
\hline How & Como? & $\begin{array}{l}\text { Tirando } 1 \text { hora do turno diário dos funcionários para ser } \\
\text { ministrado a aula sobre o sistema aos mesmos. }\end{array}$ \\
\hline How & Quanto? & $\mathrm{R} \$ 1.200,00$ \\
\hline
\end{tabular}

Fonte: Autores, 2021

RC: 101923

Disponível em:

https://www.nucleodoconhecimento.com.br/administracao/implementacao-do- 
No quadro 03, há o primeiro passo para aplicação do sistema VAC na empresa, por meio do departamento de Recursos Humanos que em 5 dias tirou 1 hora de tempo de seus funcionários para aplicar o estudo sobre o sistema, que ocorreu na primeira semana de setembro, com um custo total de $R \$ 1.200,00$.

A empresa confirmou que quando seus colaboradores obtêm conhecimento sobre as novidades da organização, as chances de sucesso foram maiores, portanto, esperava-se que esta primeira etapa do processo de introdução do sistema de atravessamento constante fosse fundamental para seguir o fluxo das etapas seguintes.

\subsubsection{ALTERAR O LAYOUT DA ÁREA DE PRODUÇÃO}

Layout é a forma a partir da qual os colaboradores e maquinários ficam dispostos no local de produção, e deve ser mudado para que se utilize o melhor espaço, resultando em um processo mais efetivo. Quando o layout da organização está disposto de forma inadequada, todo fluxo de produção é atrapalhado e atrasado, por isso, a adequação do layout da área produtiva ao sistema VAC é uma importante etapa para a implementação do sistema na organização.

Quadro $04-5 w 2 h$ - Alterar o layout da área de produção

\begin{tabular}{|l|l|l|}
\hline \multicolumn{3}{|c|}{ Alterar o layout da área de produção } \\
\hline What & O quê? & $\begin{array}{l}\text { Mudar a disposição dos funcionários e maquinários da área } \\
\text { de produção }\end{array}$ \\
\hline Why & Por quê? & $\begin{array}{l}\text { Para que o colaborador e máquina utilize de um melhor } \\
\text { espaço, acelerando o processo produtivo. }\end{array}$ \\
\hline Where & Onde? & TS Indústria de Etiquetas \\
\hline When & Quando? & Segunda semana de setembro de 2021 \\
\hline Who & Quem? & Diretoria da empresa TS \\
\hline How & Como? & Dispondo o maquinário da área de produção e funcionários \\
\hline
\end{tabular}

RC: 101923

Disponível em:

https://www.nucleodoconhecimento.com.br/administracao/implementacao-do- 
de forma que ambos se entrosem para uma produção mais efetiva.

How Quanto? $\mathrm{R} \$ 800,00$

Much

Fonte: Autores, 2021.

No quadro 04, temos como etapa a mudança de layout da área de produção que, através da diretoria da empresa, foi introduzida a partir da segunda semana de setembro, com o custo de $\mathrm{R} \$ 800,00$ para a empresa.

Geralmente, uma área de produção mal organizada gera atraso na produção e atrapalha todo processo da organização. Por esse motivo, essa mudança foi importante e foi elaborada atentando-se aos seguintes passos: integrou os colaboradores e maquinários de forma em que fiquem entrosados; aplicou uma distância mínima para que houvesse somente o movimento necessário; precisou-se de um fluxo contínuo para que não houvesse atrasos nos processos; e visou a segurança e satisfação do colaborador, pois um funcionário satisfeito produz com qualidade e maior quantidade.

\subsubsection{BALANCEAR O FLUXO DE PRODUÇÃO}

O balanceamento da produção nada mais é que fazer com que cada atividade produza quantidades iguais, seja do grupo anterior ou posterior. Um bom balanceamento evita paradas, ou seja, com a divisão do setor em grupos menores de cinco a quatro colaboradores, a organização realizará sua produção com mais rapidez e eficiência, passando a ter uma produção por tempo e não por quantidade, adaptando-se assim ao sistema VAC.

RC: 101923

Disponível em:

https://www.nucleodoconhecimento.com.br/administracao/implementacao-do- 
Quadro 05 - 5w2h - Balancear o fluxo de produção

\section{Balancear o fluxo de produção}

\begin{tabular}{|l|l|l|}
\hline What & O quê? & Dividir o setor de produção em grupos menores \\
\hline Why & Por quê? & Para que se obtenha um fluxo de produção mais rápido \\
\hline Where & Onde? & TS Indústria de Etiquetas \\
\hline $\begin{array}{l}\text { When } \\
\text { Who }\end{array}$ & Quando? & Terceira semana de Setembro de 2021 \\
\hline Chow & Como? & $\begin{array}{l}\text { Na área de produção deve-se dividir os colaboradores em } \\
\text { pequenos grupos para que se acelere a produtividade }\end{array}$ \\
\hline $\begin{array}{l}\text { How } \\
\text { Much }\end{array}$ & Quanto? & $\mathrm{R} \$ 00,00$ \\
\hline
\end{tabular}

Fonte: Autores, 2021

No quadro 05, observa-se mais uma etapa das ações interventivas, balanceando o fluxo de produção e dividindo o setor de produção em grupos menores. A diretoria da empresa precisou alinhar os colaboradores de forma que, em pequenos grupos, a produção fosse mais efetiva. Esta ação foi feita também na terceira semana de setembro e sem custos para a organização.

Com o balanceamento do fluxo de produção, a produção ficou mais efetiva e ágil, pois pequenos grupos de três ou quatro colaboradores estarão sempre entregando e recebendo uma parte da produção em períodos de tempo determinados.

\subsubsection{INTRODUZIR O TRANSPORTE ENTRE CÉDULAS (KANBAN)}

O transporte entre cédulas na TS funcionará de forma que lotes de etiquetas avançarão para cada grupo em um tempo de 30 minutos, portanto, a cada 30 minutos terão lotes de etiquetas a serem produzidas e lotes prontos. Reduzir o Setup é um dos pontos importantes do sistema VAC, pois com o tempo reduzido de

RC: 101923

Disponível em:

https://www.nucleodoconhecimento.com.br/administracao/implementacao-dosistema 
produção, o lote de etiquetas, sai com mais rapidez do setor de produção, fazendo com que as entregas sejam realizadas no prazo.

Quadro 06 - Introduzir o transporte entre cédulas (kanban)

\begin{tabular}{|l|l|l|l|}
\hline \multicolumn{3}{|l|}{ Balancear o fluxo de produção } \\
\hline What & O quê? & Dividir o setor de produção em grupos menores \\
\hline Why & Por quê? & Para que se obtenha um fluxo de produção mais rápido \\
\hline Where & Onde? & TS Indústria de Etiquetas \\
\hline When & Quando? & Terceira semana de Setembro de 2021 \\
\hline Who & Quem? & Chefe da área de produção \\
\hline How & Como? & Na área de produção deve-se dividir os colaboradores em \\
\hline How & Quanto? & R $\$ 00,00$ \\
\hline Much & & \\
\hline Introduzir o transporte entre cédulas (kanban) \\
\hline What & O quê? & Deslocador produzidos em lotes na área de produção \\
\hline Why & Por quê? & Para agilizar o processo de produção \\
\hline Where & Onde? & TS Indústria de Etiquetas \\
\hline When & Quando? & Primeira semana de outubro de 2021 \\
\hline Who & Quem? & Diretoria da empresa TS \\
\hline How & Como? & Através de carrinhos com lotes a produzir e produzidos que \\
\hline How & Quanto? & R $\$ 1.000,00$ \\
\hline Much & & \\
\hline
\end{tabular}

Fonte: Autores, 2021

No quadro 06, observa-se a aplicação da etapa de introdução do transporte entre cédulas no setor de produção, que foi feito a partir da primeira semana de outubro,

RC: 101923

Disponível em:

https://www.nucleodoconhecimento.com.br/administracao/implementacao-dosistema 
em um período de 4 dias por meio da diretoria da empresa TS, com um custo de $R \$$ 1.000 .

Esperava-se que o transporte entre cédulas agilizasse o processo produtivo das etiquetas e que, apesar do custo a organização, trouxesse benefícios maiores com o sucesso desta etapa, pois, assim, além da rapidez no processo, seus colaboradores obtiveram um melhor desempenho e maior comodidade no trabalho.

\subsubsection{APLICAR O SISTEMA VAC NA EMPRESA}

Como já vimos anteriormente, esse sistema não funciona sem que haja um processo a ser seguido. Para que funcione como esperado é necessário seguir as etapas anteriores até sua devida aplicação na empresa.

O sistema VAC foi aplicado na organização visando a diminuição do período de tempo entre o pedido do cliente e a entrega do mesmo e por meio da ferramenta $5 \mathrm{w} 2 \mathrm{~h}$ visualizou-se as formas e todas as informações necessárias para que a introdução do sistema se adequasse a empresa.

Quadro 07 - Aplicar o sistema VAC na empresa

\section{Balancear o fluxo de produção}

\begin{tabular}{|l|l|l|}
\hline What & O quê? & Dividir o setor de produção em grupos menores \\
\hline Why & Por quê? & Para que se obtenha um fluxo de produção mais rápido \\
\hline Where & Onde? & TS Indústria de Etiquetas \\
\hline When & Quando? & Terceira semana de Setembro de 2021 \\
\hline Who & Quem? & Chefe da área de produção \\
\hline How & Como? & Na área de produção deve-se dividir os colaboradores em \\
& & pequenos grupos para que se acelere a produtividade \\
\hline How & Quanto? & $\mathrm{R} \$ 00,00$ \\
\hline Much & & \\
\hline
\end{tabular}

RC: 101923

Disponível em:

https://www.nucleodoconhecimento.com.br/administracao/implementacao-do- 


\begin{tabular}{|c|c|c|}
\hline \multicolumn{3}{|c|}{ Aplicar o sistema VAC na empresa } \\
\hline What & O quê? & VAC - Velocidade de atravessamento Constante \\
\hline Why & Por quê? & Para que a empresa atenda a demanda de pedidos no prazo \\
\hline Where & Onde? & TS Indústria de Etiquetas \\
\hline When & Quando? & Segunda semana de outubro de 2021 \\
\hline Who & Quem? & Diretoria da empresa TS e Chefe da área de produção \\
\hline How & Como? & $\begin{array}{l}\text { Seguindo as etapas anteriores que são parte do sistema VAC, e } \\
\text { através de carrinhos que avançaram para cada grupo em } \\
\text { períodos de } 30 \text { minutos. }\end{array}$ \\
\hline $\begin{array}{l}\text { How } \\
\text { Much }\end{array}$ & Quanto? & $\mathrm{R} \$ 1.800,00$ \\
\hline \multicolumn{3}{|c|}{ Introduzir o transporte entre cédulas (kanban) } \\
\hline What & O quê? & Deslocador produzidos em lotes na área de produção \\
\hline Why & Por quê? & Para agilizar o processo de produção \\
\hline Where & Onde? & TS Indústria de Etiquetas \\
\hline When & Quando? & Primeira semana de outubro de 2021 \\
\hline Who & Quem? & Diretoria da empresa TS \\
\hline How & Como? & $\begin{array}{l}\text { Através de carrinhos com lotes a produzir e produzidos que } \\
\text { serão repassados a cada grupo do processo de produção }\end{array}$ \\
\hline $\begin{array}{l}\text { How } \\
\text { Much }\end{array}$ & Quanto? & $\mathrm{R} \$ 1.000,00$ \\
\hline
\end{tabular}

Fonte: Autores, 2021.

O Quadro 07 traz ações que visam a concretização da implementação do Sistema VAC na organização. O sistema é formado de etapas que devem ser seguidas para que o VAC funcione devidamente. Será colocado em prática na segunda semana de outubro, por meio da diretoria da empresa, juntamente com o chefe da área de produção, com o custo de $R \$ 1.800,00$.

RC: 101923

Disponível em:

https://www.nucleodoconhecimento.com.br/administracao/implementacao-do$\underline{\text { sistema }}$ 
Portanto, por meio da implementação e conclusão de todas as etapas desse sistema, se espera que os todos os problemas da organização sejam resolvidos, e assim, a empresa possa entregar suas encomendas dentro do prazo previsto à sua carteira de clientes, obtendo mais lucros, confiabilidade e crescimento.

\section{CONSIDERAÇÕES FINAIS}

Após os levantamentos e análise dos problemas, foram identificados os principais pontos que necessitam de ajustes na empresa TS Indústria de Etiquetas e Comércio de Equipamentos de Informática Ltda. A partir destes, observou-se que o planejamento não era realizado de forma eficaz, necessitando, portanto, de melhorias, desde o planejamento estratégico no treinamento de colaboradores, até o momento em que a satisfação do cliente é alcançada.

Diante desse contexto, o objetivo geral deste estudo foi propor e apresentar sugestões, utilizando ferramentas e métodos para melhorias no planejamento e desenvolvimento do sistema de produção da empresa TS Indústria de Etiquetas e Comércio de Equipamentos de Informática Ltda.

$\mathrm{O}$ presente artigo, foi norteado e visou responder à seguinte pergunta: como a implementação do sistema VAC (Velocidade de Atravessamento Constante) pode contribuir com a maximização do atendimento no prazo da demanda da carteira de pedidos na indústria de etiquetas? Após as análises realizadas na referida empresa e a elaboração de ações interventivas, observou-se que, se a organização aplicar a proposta de implementação e seguir cada etapa desse sistema, o eventual problema da área de produção na indústria de etiquetas será melhorado, comprovando que o sistema VAC contribui para a maximização do atendimento no prazo da demanda da carteira de pedidos na indústria de etiquetas.

Portanto, é importante a implantação das melhorias propostas neste trabalho, para que a empresa continue fazendo frente aos concorrentes, com diferencial competitivo e estratégico.

RC: 101923

Disponível em:

https://www.nucleodoconhecimento.com.br/administracao/implementacao-dosistema 


\section{REFERÊNCIAS}

ANDERSON, D.J. Kanban: Mudança Evolucionária de Sucesso para Seu Negócio de Tecnologia. Sequim: Blue Hole Press, 2011.

ANTUNES, Junico. Sistemas de Produção: conceitos e práticas para projetos e gestão da produção enxuta. 3. ed. Porto Alegre, RS: Bookmann, 2018.

ASSIS, Rui. Tempos de fabricação degressivos resultantes da experiência. 2011. Disponível em: <http://www.rassis.com/artigos/Curvas_experiencia.pdf>. Acesso em: 21 de setembro de 2021.

BALLOU, Ronald. H. Logística empresarial: transportes, administração de materiais e distribuição física. São Paulo: Atlas, 2011.

COSTA, Eliezer Arantes da. Gestão estratégica: da empresa que temos para a empresa que queremos. 5ed. São Paulo: Saraiva, 2017.

ESPINHA, Roberto Gil. E-book Kanban: aprendendo a gerenciar fluxos de trabalho. Artia, 2019.

FURLANI, Kleber. Estudos de Tempos e Métodos. Disponível em: < https://furlani.eng.br/2020/07/19/estudo-de-tempos-e-metodos-2/>. Acesso em 29 de setembro de 2021.

JACOBSEN, A. L. Introdução à Administração. Florianópolis: Departamento de Ciências da Administração/UFSC, 2017.

JAISWAL, A.; SANE, S. M.; KARANDIKAR, V. Improving Productivity in a Paint Industry using Industrial Engineering Tools and Techniques. International Journal of Advance Industrial Engineering, n. 11, 2016.

RC: 101923

Disponível em:

https://www.nucleodoconhecimento.com.br/administracao/implementacao-do-

$\underline{\text { sistema }}$ 
MARCONI, Marina de Andrade; LAKATOS, Eva Maria. Metodologia científica. 7. ed. São Paulo: Atlas, 2018. 373 p.

MARQUES, J. Quais os Tipos de Planejamento em uma Organização?. 2015. Disponível em: < <ttps://www.jrmcoaching.com.br/blog/quais-os-tipos-deplanejamento-em-uma-organizacao/> Acesso em 20 de setembro de 2021.

MOURA, R. A. A simplicidade do controle da produção. 7 ed. São Paulo: Instituto de Movimentação e Armazenagem de Materiais/ Imam, 2007

NEGREIROS, Raquel Ferreira de; LIMA, Roberta Nayhane de. Projeto de engenharia de métodos numa fábrica de sorvetes. Seprone - Simpósio de Engenharia de Produção da Região Nordeste, v. 01, p.1 - 11, 2011.

NUNES, S. Gestão de produção e operações. Batatais: Claretiano, 2013.

PRESTES, Maria Luci de Mesquita. A pesquisa e a construção do conhecimento científico: do planejamento aos textos, da escola à academia. 4. ed. rev., atual. eampl. São Paulo: Rêspel, 2011.

ROCHA, R.P. \& OLIVEIRA, C.C. Balanceamento de Linha: Estudo de caso na produção de Boneless $L e g(B L)$ em um frigorífico de aves. In: ENCONTRO NACIONAL DE ENGENHARIA DE PRODUÇÃO (ENEGEP) XXVII, 2007, Foz Iguaçu/PR. Anais... Foz Iguaçu/PR: Associação Brasileira de Engenharia de $\begin{array}{llll}\text { Produção } & \text { (ABEPRO). } & 2017 . & \text { Disponível }\end{array}$ $<72$ http.// fi.abepro.org.br/biblioteca/enegep2007_tr570427_0532.pdf>. Acesso em 10 de setembro de 2021.

SELEME, Robson; STADLER, Humberto. Controle da qualidade: As ferramentas essenciais. Curitiba: Ibpex, 2012.

SILVA, M. L. V. A importância do layout dentro das indústrias para o aumento da produtividade.

Disponível

em: $<$ http://

RC: 101923

Disponível em:

https://www.nucleodoconhecimento.com.br/administracao/implementacao-do- 
www.techoje.com.br/site/techoje/categoria/detalhe_artigo/1661>. Acesso em 21 de Setembro de 2021.

SISTEMA VAC: Site oficial da empresa. Disponível em: <http://www.vac.com.br>. Acesso em 15 de setembro de 2021.

SOUEID, Mohamad; ALVES, Wendel. Ebook Kanban na prática para gestores. Cia Makers, 2020. Disponível em:< https://www.ciamakers.com/kanban.pdf> acesso em 29 de setembro de 2021.

TUBINO, D.F. Planejamento e Controle da Produção - Teoria e Prática. São Paulo: Atlas, 2017

ZANELLA, Liane Carly Hermes. Metodologia de Pesquisa. 2. Ed. Florianópolis: Departamento de ciências da Administração/UFSC, 2013.

Enviado: Outubro, 2021.

Aprovado: Novembro, 2021.

RC: 101923

Disponível em:

https://www.nucleodoconhecimento.com.br/administracao/implementacao-dosistema 